\title{
Editorial: The Power of Citizen Seismology: Science and Social Impacts
}

\author{
Kate Huihsuan Chen ${ }^{1 *}$, Remy Bossu ${ }^{2}$ and Wen-Tzong Liang ${ }^{3}$ \\ ${ }^{1}$ Department of Earth Sciences, National Taiwan Normal University, Taipei, Taiwan, ${ }^{2}$ European-Mediterranean Seismological \\ Centre, Paris, France, ${ }^{3}$ Institute of Earth Sciences, Academia Sinica, Nankang, Taiwan
}

Keywords: citizen seismology, social media, smart phone, earthquake monitoring, crowdsourced, education

\section{Editorial on the Research Topic}

\section{The Power of Citizen Seismology: Science and Social Impacts}

Citizen seismology that refers to research collaborations between seismologists and non-scientists volunteers is a growing field. In a place with poor coverage of seismic network, such collaborations provide an increasingly integrated data collections that make a real-time monitoring of earthquake possible. In an area with dense enough seismic network, it allows more public involvement that helps on the awareness and preparation toward seismic impact. The recently published special issue of "The power of citizen seismology: Science and social impacts" brings together experiences from different countries with different aspects. Below is a brief overview for their successes, challenges, and prospects.

The significant information of earthquakes can be gained through social media and smartphone. USGS "Did you feel it?" is one of the well-developed systems that collects shaking and damage reports from internet users shortly after the felt events in California, since 1999. In this special issue, Quitoriano and Wald demonstrate how eyewitnesses' observations guide the media and the public toward a more suitable way to describe the variations of earthquake shaking. In conjunction with "Did you feel it," the US based smartphone app "MyShake" delivers information for early warning purpose in California since 2019; In the article by Strauss et al., the context, programmatic elements, and challenges at the intersection of science, public communication, and technology is outlined. "Earthquake Network" app also collected information from smartphones globally for early warning purpose, which the history, main features, and problems are fully addressed in the article by Finazzi. Another powerful, EU based crowdsourced tool in EMSC website and LastQuake app are documented by Bondar et al., where they addressed the performance of EMSC-based CsLoc services on locating earthquake precisely and the development directions. Fallou et al. introduced how the users' experience helped on scientific discoveries through LastQuake, during a surprisingly large number of earthquake swarm in Mayotte in 2018. While Fallou et al. highlighted the importance of public communication during the earthquake, Bossu et al. and Yen et al. focused on augmenting data collection and rapid situation awareness for the destructive earthquake and tsunami.

Meanwhile, the availability of cheap sensors (Raspberry Shake or Quake Catcher Network) opened the way not only to provide advanced scientific exploration but also to structure communities of amateurs seismologists. The good examples include the increase in earthquake detectability down to magnitude 1.5-2.0 for the earthquakes in Haiti (by Calais et al.) and a new magnitude equation using the data collected during the 2014 M7.8 Gorkha earthquake in Nepal (by Subedi et al.). Jeddi et al. on the other hand, demonstrates the monitoring of earthquake,

cryoseisms, and landslides in Arctic. In Taiwan, a near-real time earthquake competition game was

Chen $\mathrm{KH}$, Bossu R and Liang W-T (2020) Editorial: The Power of Citizen Seismology: Science and Social Impacts. Front. Earth Sci. 8:610813. doi: 10.3389/feart.2020.610813 
developed for the citizen to process the location, magnitude, seismic intensity, and focal mechanisms for each inland $M>4$ earthquakes, as introduced by Chen et al. With a lot more data collected from witnesses and volunteers, how the citizen gains a better understanding of seismology? In this special issue, there are also several articles focusing on the educational purpose including Bravo et al., Tang et al., and Chen et al. They address different classroom activities or online platform that may help the learning of real seismic data and scientific findings from the citizen contribution.

In summary, the innovative technologies have made the data exchange between citizens and the seismological community possible. With the growing volume of data, crowdsourced detections improve early warning of earthquake, rapid information education, and public awareness. For promoting citizen seismology in the future, a better link with urban seismology (as addressed in Diaz et al.) and improvement on the relationship between scientific facts, media reporting, and public communication (as addressed by Camilleri et al.) should be all considered. With the integrated efforts, an improved dialogue between science and society as well as the societal value of seismology can be expected.

\section{AUTHOR CONTRIBUTIONS}

$\mathrm{KC}$ wrote this article, while $\mathrm{RB}$ and $\mathrm{W}$-TL provided comments for improvement on this brief overview.

Conflict of Interest: The authors declare that the research was conducted in the absence of any commercial or financial relationships that could be construed as a potential conflict of interest.

Copyright (c) 2020 Chen, Bossu and Liang. This is an open-access article distributed under the terms of the Creative Commons Attribution License (CC BY). The use, distribution or reproduction in other forums is permitted, provided the original author(s) and the copyright owner(s) are credited and that the original publication in this journal is cited, in accordance with accepted academic practice. No use, distribution or reproduction is permitted which does not comply with these terms. 